OPEN ACCESS

Edited by:

Mehdi Razzaghi-Abyaneh,

Pasteur Institute of Iran, Iran

Reviewed by:

Eva-Guadalupe Lizárraga-Paulín,

Instituto Tecnológico y de Estudios

Superiores de Monterrey Campus

Estado de México, Mexico

Paula Cristina Azevedo Rodrigues,

Polytechnic Institute of Braganca,

Portugal

${ }^{*}$ Correspondence:

Yang Liu and Xiaofeng Dai,

Institute of Food Science

and Technology - Chinese Academy

of Agricultural Sciences/Key

Laboratory of Agro-Products Processing, Ministry of Agriculture,

1 Nongda South Road,

Xibeiwang, Haidian District,

Beijing 100193, China liuyang01@caas.cn;

daixiaofeng@caas.cn

tThese authors have contributed equally to this work.

Specialty section:

This article was submitted to

Food Microbiology,

a section of the journa

Frontiers in Microbiology

Received: 21 June 2015 Accepted: 14 September 2015

Published: 22 October 2015

Citation:

Ding N, Xing F, Liu X, Selvaraj JN, Wang $L$, Zhao Y, Wang Y, Guo W,

Dai $X$ and Liu Y (2015) Variation in fungal microbiome (mycobiome) and aflatoxin in stored in-shell peanuts at four different areas of China. Front. Microbiol. 6:1055. doi: 10.3389/fmicb.2015.01055

\section{Variation in fungal microbiome (mycobiome) and aflatoxin in stored in-shell peanuts at four different areas of China}

\author{
Ning Ding ${ }^{\dagger}$, Fuguo Xing ${ }^{\dagger}, X_{i a o}$ Liu $^{\dagger}$, Jonathan N. Selvaraj, Limin Wang, Yueju Zhao, \\ Yan Wang, Wei Guo, Xiaofeng Dai* and Yang Liu*
}

Institute of Food Science and Technology - Chinese Academy of Agricultural Sciences/Key Laboratory of Agro-Products Processing, Ministry of Agriculture, Beijing, China

The contamination of peanuts with Aspergillus sp. and subsequently aflatoxins is considered to be one of the most serious safety problems in the world. Mycobiome in peanuts is critical for aflatoxin production and food safety. To evaluate the biodiversity and ecological characteristics of whole communities in stored peanuts, the barcoded Illumina paired-end sequencing of the internal transcribed spacer 2 (ITS2) region of rDNA was used to characterize the peanut mycobiome monthly over a period of 1 year at four main peanut grown areas, i.e., Liaoning (LN, North East), Shandong (SD, East), Hubei (HB, Central), and Guangdong (GD, South) provinces. The fungal diversity of peanuts stored in SD was the highest with 98 OTUs and 43 genera, followed by LN, HB and GD. In peanuts stored in SD, Rhizopus, Emericella, and Clonostachys were predominant. In peanuts from LN, Penicillium, Eurotium, and Clonostachys were abundant. In peanuts from HB, Penicillium, Eurotium, and Aspergillus were higher. In GD peanuts, Eurotium, Aspergillus, and Emericella were mainly seen. The abundances of Aspergillus in LN, SD, $\mathrm{HB}$, and GD were $0.53,6.29,10.86$, and $25.75 \%$, respectively. From the North of China to the South, that increased over the latitude, suggesting that the higher temperature and relative humidity might increase the risk of peanuts contaminated with Aspergillus and aflatoxins. During the storage, Aspergillus levels were higher at 7-12 months than in 0-6 months, suggesting that the risk increases over storage time. At 7-10 months, $\mathrm{AFB}_{1}$ was higher in four areas, while declined further. The reduction of $\mathrm{AFB}_{1}$ might be attributed to the inhibition and degradation of $\mathrm{AFB}_{1}$ by Aspergillus niger or to the combination with the compounds of peanuts. This is the first study that identified the mycobiome and its variation in stored peanuts using ITS2 sequencing technology, and provides the basis for a detailed characterization of whole mycobiome in peanuts.

Keywords: fungal microbiome, mycobiome, $\mathrm{AFB}_{1}$, peanuts, storage, ITS sequencing

\section{Introduction}

Mycotoxins are secondary metabolites produced by different fungal species when they infect the foods and feeds. Mycotoxins contamination is commonly seen in the human food chain, posing great threat to public health and the common mycotoxins are aflatoxin, deoxynivalenol, zearalenone, fumonisins, ochratoxin, patulin, and ergot alkaloids (Hussein and Brasel, 2001). 
Mycotoxins are considered to be naturally occurring contaminants in peanut, maize, wheat, rice, tree nuts, dried fruit, spices, figs, crude vegetable oils, cottonseed, cocoa beans, copra, and feeds both pre and post-harvest. Mycotoxin producing fungi belong mainly to the genera Aspergillus, Fusarium, Penicillium, and Alternaria (Gonçalez et al., 2008). Presence of multiple mycotoxins in the same commodity produced by different species is very common.

Aflatoxins are the most toxic and carcinogenic in nature. Aflatoxins have both teratogenic and mutagenic properties and cause toxic hepatitis, hemorrhage, edema, immunosuppression, and hepatic carcinoma (group 1; International Agency for Research on Cancer [Iarc, \#186], 1993, 2002), especially aflatoxin $\mathrm{B}_{1}\left(\mathrm{AFB}_{1}\right)$. In China, aflatoxins contamination in peanuts and peanut products has been an alarming problem, although they have been found mostly in low level (Ding et al., 2012). In the last decade, more than $28 \%$ of food imported from China was rejected by RASFF (Food and Feed Safety Alerts-European Commision) due to aflatoxin contamination ${ }^{1}$.

Aspergillus flavus growth and subsequently aflatoxin production in peanuts depend on several factors, such as geographical region, seasonal variation and the environmental factors during planting and storage. Tropical and subtropical regions, with high temperatures and high relative humidity (RH), are highly favorable for A. flavus growth and aflatoxin production (Smith and Ross, 1991; Giorni et al., 2009). In addition, some filamentous fungi also could influence A. flavus growth and aflatoxin accumulation. For example, Aspergillus niger significantly suppressed $A$. flavus growth, sporulation and reduced the level of $\mathrm{AFB}_{1}$ (Krishnamurthy and Shashikala, 2006; Cvetnić and Pepeljnjak, 2007; Xu et al., 2013). Aspergillus oryzae inhibited $\mathrm{AFB}_{1}$ biosynthesis during the fermentation of soy sauce (Maing et al., 1973); Aspergillus chevalieri and Aspergillus candidus reduced $\mathrm{AFB}_{1}$ production by Aspergillus parasiticus in rice (Boller and Schroeder, 1973, 1974); and Alternaria sp., Cladosporium sp., and Mucor sp. decreased $\mathrm{AFB}_{1}$ production by A. flavus NRRL 3251 (Cvetnić and Pepeljnjak, 2007). Therefore, it is necessary to characterize the fungal microbiome of peanuts and its variations during storage. Nakai et al. (2008) evaluated the mycoflora and occurrence of aflatoxins in stored peanut samples from Brazil and found that Fusarium sp. and Aspergillus sp. were highly predominance with the presence of five other genera. However, the approach used by this group provided only a limited snap shot of the fungal members of the microbiome. In recent years, high-throughput sequencing technologies have opened new frontiers in microbial community analyses by providing an economic and efficient means to identify the microbial phylotypes in samples. Studies have revolutionized our understanding of the microbial communities present in our human bodies (Costello et al., 2009; Grice et al., 2009; Ghannoum et al., 2010), soils (Roesch et al., 2007; Lauber et al., 2009) and deep seas (Sogin et al., 2006). The internal transcribed spacer 2 (ITS2), which is an excellent phylogenetic marker suitable for fungal taxon assignment (Mello et al.,

\footnotetext{
${ }^{1}$ https://webgate.ec.europa.eu/rasff- window/portal/?event=searchForm\& cleanSearch $=1$
}

2011), has been successfully used in comparative ecology studies where it gives results that are convergent with, if not comparable to, those for other markers (Mello et al., 2011; Arfi et al., 2012). ITS-based surveys are extremely valuable because they allow the assessment of biodiversity and ecological characteristics of whole communities or individual microbial taxa.

Although some previous studies have evaluated the mycoflora in stored peanuts using traditional isolation, enumeration and identification, the approach used by these researches provided only a limited snap shot of the fungal members of the microbiome. To obtain a more comprehensive profile of the fungal microbiome (mycobiome), we used the barcoded Illumina paired-end sequencing (BIPES) method (Zhou et al., 2011) in this study to characterize the mycobiome and its variation in stored peanuts at four different areas, Liaoning, Shandong, Hubei, and Guangdong. This is the first study that characterizes the mycobiome and its variation in stored peanuts using ITS2 sequencing. The findings of this study are likely to encourage the implementation and design of mold and aflatoxin management strategies.

\section{Materials and Methods}

\section{Ethics Statement}

Specific permission was not needed for our field studies. The peanuts variety used in our field study was main cultivar in Liaoning (LN), Shandong (SD), Hubei (HB), and Guangdong (GD) province. No transgenic or mutant plant has been used in our study. Also we confirm that the field studies did not involve endangered or protected species.

\section{Sample Preparation}

Peanuts (Virginia type) were obtained from four major peanut production areas in China, which are Jinzhou city of Liaoning province (North East), Linyi city of Shandong province (East), Xiangyang city of Hubei province (Central), and Zhanjiang city of Guangdong province (South), located in the Northeast plain, Yellow River valley, the center of Yangtze River valley and the Southeast Coastal areas, respectively. After harvest and drying, the peanuts were placed in $25 \mathrm{~kg}$ bags (a total of three bags each area), piled up on a wooden frame, and stored for a period of 12 months in a warehouse with ventilation $14 \mathrm{~h}$ each day (8:00-22:00). Before storage, the warehouse was sterilized with $30 \mathrm{mg} / \mathrm{m}^{3}$ ozone. Samples were removed monthly from different points of each bag until completing a sample of $1 \mathrm{~kg}$ (Nakai et al., 2008). Three samples (triplicates) were collected each month (0-12 months) in each area, for a total 156 samples (three samples/area/month $\times 4$ area $\times 13$ months $=156$ samples), and were mailed in hermetic bags to our lab in Beijing. Each sample was analyzed for aflatoxins in peanut kernels. Three samples of one area each month were mixed, thus 52 samples were analyzed for mycobiome. The water activities of peanut kernels were determined by using Aqualab Series 4 (Decagon Devices, Inc., Pullman, WA, USA). 


\section{Total Microbiome Genomic DNA Extraction}

One hundred grams of peanut kernels from the collected samples washed in $100 \mathrm{ml}$ sterile water and the water samples were collected and vacuum-filtered through $0.22 \mu \mathrm{m}$ filters within. The filters containing sample were placed in $50 \mathrm{ml}$ tubes and stored at $-20^{\circ} \mathrm{C}$ until analysis. The MoBio Power Water ${ }^{\circledR}$ DNA Isolation Kit (MoBio Laboratories, Inc., Carlsbad, CA, USA) was used to extract the genomic DNA from the filters according to manufacturer's instruction. The final DNA elution was performed using sterile deionized water. DNA quality and quantity were measured by spectrophotometric quantification in a NanoDrop 1000 (Thermo Fisher Scientific, Inc., Newark, DE, USA) and by agarose gel electrophoresis. Extracted DNA was stored at $-80^{\circ} \mathrm{C}$.

\section{PCR Amplification and ITS2 Sequencing}

Fungal universal primers ITS2F (5'-GCATCGATGAAGAAC GCAGC-3') and ITS2R (5'-TCCTCCGCTTATTGATATGC-3') were used to amplify the ITS2 region of fungal rDNA. PCR reactions were carried out in a total reaction volume of $30 \mu \mathrm{l}$ consisting of $15 \mu \mathrm{l}$ of Phusion High-Fidelity PCR Master Mix (New England Biolabs, Inc., Ipswich, MA, USA), $0.2 \mu \mathrm{M}$ of forward and reverse primers, and $10 \mathrm{ng}$ of template DNA. The PCR amplification program consisted of a initial heating to $98^{\circ} \mathrm{C}$ for $1 \mathrm{~min}, 30$ cycles of denaturation at $98^{\circ} \mathrm{C}$ for $10 \mathrm{~s}$, annealing at $50^{\circ} \mathrm{C}$ for $30 \mathrm{~s}$ and extension at $72^{\circ} \mathrm{C}$ for $60 \mathrm{~s}$, followed by a 5 -min extension at $72^{\circ} \mathrm{C}$. GeneJET Gel Extraction Kit (Thermo Scientific, South Logan, UT 84321, USA) was used to purify the amplified products according to the manufacturer's recommendations. Of 52 peanut samples, 39 samples were successfully amplified. Amplicons were quantified and sequencing libraries were generated using NEB Next Ultra DNA library Prep Kit for Illumina (New England Biolabs, Inc., USA) according to manufacturer's instructions. The amplicon libraries were subsequently sequenced on an Illumina MiSeq platform at Novogene (Novogene, Beijing, China).

\section{Bioinformatics Analyses}

FLASH (Magoc and Salzberg, 2011) was used to merge the paired-end reads from the original DNA fragments. QIIME software package ${ }^{2}$ and UPARSE pipeline were used to analyze the reads and pick operational taxonomic units (OTUs; Gillever et al., 2010). Sequences were assigned to OTUs at $97 \%$ similarity. A representative sequence for each OTU was picked and used the RDP classifier (Wang et al., 2007) to assign taxonomic data to each representative sequence. In order to reveal Alpha diversity, rarefaction curves were generated based on these two metric: the observed species metric is simply the count of unique OTUs found in the sample, and Shannon index.

\section{Determination of Aflatoxins}

Aflatoxins in the peanuts were detected by the HPLC (high performance liquid chromatography). The specific methodology and technology were refer to Chinese standard methods (Liu et al., 2006) and AOAC method 994.08 (AOAC AOAC International, 2000) with minor modifications. In this research,

${ }^{2} \mathrm{http} / / /$ iime.org/
$50 \mathrm{~g}$ peanut kernels were mixed, kept in hermetic bags, and stored at $-20^{\circ} \mathrm{C}$ until analysis. Peanut kernels $(5 \mathrm{~g})$ were extracted with $15 \mathrm{ml}$ of acetonitrile:water (84:16, v/v). After ultrasonic extraction $\left(50^{\circ} \mathrm{C}, 10 \mathrm{~min}\right)$ and filtration with double-layer slow quantitative filter paper, $4 \mathrm{ml}$ of the resulting filtrate was collected in $10 \mathrm{ml}$ test tube, and then mixed with $2 \mathrm{ml}$ petroleum ether. The mixture was blended using vortex control for $30 \mathrm{~s}$ and stood for $15-20 \mathrm{~min}$ to separate into two layers. The lower solution $(3 \mathrm{ml})$ was collected, and mixed with $8 \mathrm{ml}$ pure water and further filtered through a $0.45 \mu \mathrm{m}$ organic membrane. Extracts $(8 \mathrm{ml})$ were passed through immunoaffinity columns (ToxinFast Columns, Cat. No. HCM0125, HuaanMagnech Biotech, Beijing, China) with a flow rate of one droplet per second and eluted using $2 \mathrm{ml}$ of methanol into glass tubes. The eluate was evaporated to dryness under a stream of nitrogen gas at $60^{\circ} \mathrm{C}$. The purified extract was re-dissolved with $1 \mathrm{ml}$ of acetonitrile: water (15: 85, v/v) and quantified by HPLC-FD. This method is applicable for determination of afltoxins $B_{1}, B_{2}, G_{1}$, and $G_{2}$ at $\geq 1 \mathrm{ng}$ total aflatoxins/g in raw peanuts.

High performance liquid chromatography analysis was performed by using Waters 2695 (Waters Corporation, Milford, MA, USA) coupled to a Waters 2475 fluorescence detector ( $\lambda$ exc $360 \mathrm{~nm} ; \lambda \mathrm{em} 440 \mathrm{~nm}$ ) and a post-column derivation system, and an Agilent TC-C18 column $(250 \mathrm{~mm} \times 4.6 \mathrm{~mm}, 5 \mu \mathrm{m}$ particle size). The mobile phase (water:methanol:acetonitrile, 4:1:1) was pumped at a flow rate of $0.5 \mathrm{ml} / \mathrm{min}$. $\mathrm{AFB}_{1}, \mathrm{~B}_{2}, \mathrm{G}_{1}$, and $\mathrm{G}_{2}$ (Sigma-Aldrich, St. Louis, MO, USA) were used as standards. The calibration curves were set up for each type of aflatoxin by the external standard method with five standard concentrations: $\mathrm{AFB}_{1}: 1.0,2.0,5.0,10.0$, and $20.0 \mathrm{ng} / \mathrm{ml}\left(r^{2}=0.998\right) ; \mathrm{AFB}_{2}$ : $1.0,1.5,2.0,2.5$, and $4.0 \mathrm{ng} / \mathrm{ml}\left(r^{2}=0.999\right) ; \mathrm{AFG}_{1}: 2.5,3.5$, 5.0, 7.0, and $10.0 \mathrm{ng} / \mathrm{ml}\left(r^{2}=0.996\right) ; \mathrm{AFG}_{2}: 2.0,2.5,3.5$, $5.0,7.5 \mathrm{ng} / \mathrm{ml}\left(r^{2}=0.999\right)$. The HPLC quantification and detection limits were: 0.5 and $0.1 \mathrm{ng} / \mathrm{mL}$ for $\mathrm{AFB}_{1} ; 0.1$ and $0.05 \mathrm{ng} / \mathrm{mL}$ for $\mathrm{AFB}_{2} ; 2.0$ and $1.0 \mathrm{ng} / \mathrm{mL}$ for $\mathrm{AFG}_{1}$ and 0.15 and $0.05 \mathrm{ng} / \mathrm{mL}$ for $\mathrm{AFG}_{2}$. Recoveries for standard $\mathrm{AFB}_{1}, \mathrm{~B}_{2}$, $\mathrm{G}_{1}$, and $\mathrm{G}_{2}$ were $85-95,84-96,89-95,76-85 \%$, respectively. The repeatability ( $\mathrm{RSDr}, n=6$ ) ranged from 6.2 to $11.2 \%$ for $\mathrm{AFB}_{1}$, from 6.1 to $10.5 \%$ for $\mathrm{AFB}_{2}$, from 6.3 to $14.8 \%$ for $\mathrm{AFG}_{1}$, and from 6.3 to $14.3 \%$ for $\mathrm{AFG}_{2}$. The reproducibility (RSDR, $n=10$ ) ranged from 7.1 to $14.3 \%$ for $\mathrm{AFB}_{1}, 7.2$ to $14.4 \%$ for $\mathrm{AFB}_{2}, 11.8$ to $18.3 \%$ for $\mathrm{AFG}_{1}$, and 7.2 to $22.6 \%$ for $\mathrm{AFG}_{2}$.

\section{Isolation and Identification of Aspergillus Fungi from Peanut Kernels}

Approximately $30 \mathrm{~g}$ was removed from each of the samples and disinfected with $0.4 \%$ sodium hypochlorite solution for $2 \mathrm{~min}$, followed by washing with sterile distilled water for elimination of external contaminants (Berjak, 1984; Nakai et al., 2008). The first isolation was performed using Dichloran Rose Bengal Chloramphenicol agar media (DRBC; Pitt et al., 1993). Three plates containing 11 kernels were used for each sample. The plates were incubated at $28^{\circ} \mathrm{C}$ for 5 days. The colonies belonging to the genus Aspergillus were identified to the species level according to Pitt and Hocking (1997). To verify the 
results of morphological characterization and identification of fungi, 18S rDNA was amplified by PCR and sequenced. The PCR primers were ITS1 (TCCGTAGGTGAACCTGCGG) and ITS4 (TCCTCCGCTTATTGATATGC). PCR conditions were as follows: $95^{\circ} \mathrm{C}$ for $3 \mathrm{~min}, 35$ cycles at $95^{\circ} \mathrm{C}$ for $30 \mathrm{~s}, 55^{\circ} \mathrm{C}$ for $30 \mathrm{~s}$ and $72^{\circ} \mathrm{C}$ for $1 \mathrm{~min}$. Basic Local Alignment Search Tool (BLAST) was used to identify the closest affiliated sequence in the GenBank/NCBI dataset. To confirm the identification of A. flavus and A. paraciticus, these isolates were transferred to A. flavus and A. parasiticus Agar (AFPA) and incubated for 7 days unilluminated at $31^{\circ} \mathrm{C}$. On this medium A. flavus and A. parasiticus produce a bright orange reverse (Pitt et al., 1983).

\section{Degradation of $\mathrm{AFB}_{1}$ in PDB Medium by Aspergillus niger}

Twenty strains of A. niger were previously confirmed by biosynthesis and HPLC as non-producer of $\mathrm{AFB}_{1}$. One $\mathrm{ml}$ of A. niger conidia suspension (of $10^{6}$ conidia/ml) was inoculated in $50 \mathrm{ml}$ of PDB (patato $200 \mathrm{~g} / \mathrm{l}$, glucose $20 \mathrm{~g} / \mathrm{l}$ ) with $100 \mathrm{ng} / \mathrm{ml}$ of $\mathrm{AFB}_{1}$. Flasks were incubated at $28^{\circ} \mathrm{C}$ for 5 days under agitation in a ZWY-2102C incubator (Zhicheng, Shanghai, China). All treatments were tested in triplicate.

$\mathrm{AFB}_{1}$ was isolated and detected using HPLC. Briefly, $10 \mathrm{ml}$ of liquid medium was extracted with $10 \mathrm{ml}$ of chloroform, the extract was evaporated in $\mathrm{N}_{2}$ flow, and the residue was dissolved in $2 \mathrm{ml}$ of acetonitrile. The extracts were cleaned using an immunoaffinity column (ToxinFast Columns). The determination of $\mathrm{AFB}_{1}$ levels were performed by HPLC.

\section{Degradation of $\mathrm{AFB}_{1}$ in Peanuts by Aspergillus niger}

One $\mathrm{ml}$ of $A$. niger conidia suspension (of $10^{6}$ conidia/ml) was inoculated on the $50 \mathrm{~g}$ peanuts $\left(a_{\mathrm{W}} 0.90\right)$ with $62.3 \mu \mathrm{g} / \mathrm{kg}$ of $\mathrm{AFB}_{1}$. The peanut samples were incubated at $28^{\circ} \mathrm{C}$ for 5 days in an incubator. All treatments were performed in triplicate. $\mathrm{AFB}_{1}$ in peanuts was isolated and detected by the HPLC according to Section "Determination of Aflatoxins."

\section{Climatic Data}

During the storage period, climatic data such as temperature $\left({ }^{\circ} \mathrm{C}\right)$ and $\mathrm{RH}$ were recorded monthly in the regions of the experiment. Daily mean temperature is the average value of temperature at 2:00, 8:00, 14:00, and 20:00 each day. Monthly mean temperature is the average value of daily mean temperature in 1 month. The calculation of daily mean $\mathrm{RH}$ and monthly mean $\mathrm{RH}$ is similar with temperature. The temperature and $\mathrm{RH}$ in four storage areas were shown in Figure 1.

\section{Disposal of Experimental Material Contaminated with Aflatoxins}

All the peanuts and experimental material contaminated with aflatoxins were incinerated in a high-temperature incinerator (Incinerator ZDEK, CECO Corporation, Tianjin, China) at $600^{\circ} \mathrm{C}$ for $2 \mathrm{~h}$. Later the materials were discarded in special bags for further disposal.

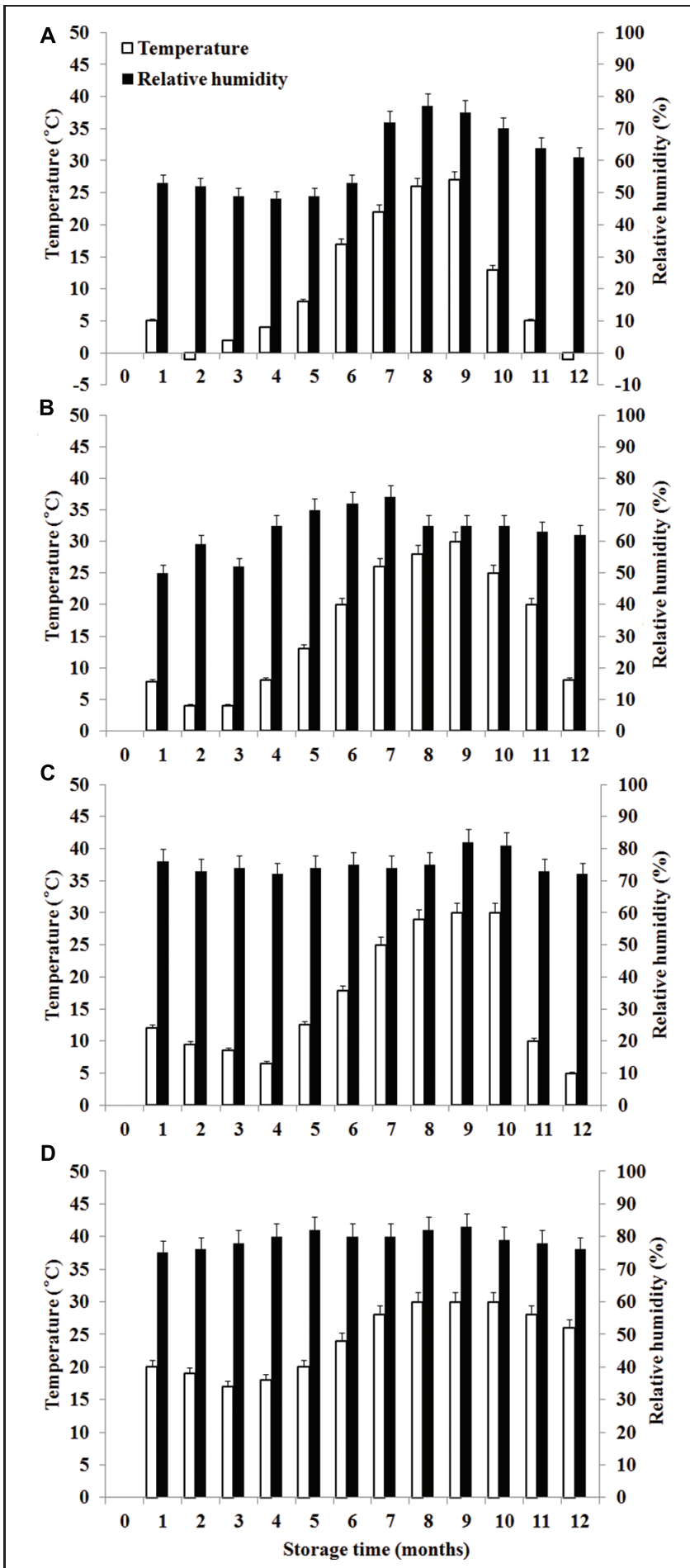

FIGURE 1 | Temperature and relative humidity in four storage areas. (A) Liaoning, (B) Shandong, (C) Hubei, (D) Guangdong.

\section{Statistical Analyses}

All the experiments results were evaluated using analysis of variance (ANOVA) for multiple comparisons followed by the Turkey test. Differences were considered significant at $p<0.05$. 
TABLE 1 | Summary of pyrosequencing analysis.

\begin{tabular}{|c|c|c|c|c|c|c|c|c|}
\hline \multirow{2}{*}{$\begin{array}{l}\text { Storage } \\
\text { Time } \\
\text { (month) }\end{array}$} & \multicolumn{2}{|c|}{ Liaoning } & \multicolumn{2}{|c|}{ Shandong } & \multicolumn{2}{|c|}{ Hubei } & \multicolumn{2}{|c|}{ Guangdong } \\
\hline & $\begin{array}{l}\text { Number of } \\
\text { reads }\end{array}$ & $\begin{array}{l}\text { Average read } \\
\text { length (bp) }\end{array}$ & $\begin{array}{l}\text { Number of } \\
\text { reads }\end{array}$ & $\begin{array}{l}\text { Average read } \\
\text { length (bp) }\end{array}$ & $\begin{array}{l}\text { Number of } \\
\text { reads }\end{array}$ & $\begin{array}{l}\text { Average read } \\
\text { length (bp) }\end{array}$ & $\begin{array}{l}\text { Number of } \\
\text { reads }\end{array}$ & $\begin{array}{l}\text { Average read } \\
\text { length (bp) }\end{array}$ \\
\hline \multicolumn{9}{|l|}{0} \\
\hline \multicolumn{9}{|l|}{01} \\
\hline \multicolumn{9}{|l|}{02} \\
\hline 03 & & & & & 13332 & 327 & 27894 & 315 \\
\hline 04 & 109021 & 312 & 54768 & 319 & 59821 & 305 & 70874 & 322 \\
\hline 05 & 68360 & 314 & 36687 & 324 & 60619 & 305 & 36187 & 316 \\
\hline 06 & 105223 & 307 & 142626 & 322 & 56238 & 307 & 81927 & 337 \\
\hline 07 & 76784 & 310 & 32989 & 318 & 41767 & 309 & 85138 & 315 \\
\hline 08 & 38472 & 337 & 60854 & 316 & 38531 & 305 & 35774 & 321 \\
\hline 09 & 53805 & 314 & 54066 & 322 & 32518 & 305 & 26291 & 348 \\
\hline 10 & 59344 & 310 & 46869 & 344 & 35420 & 315 & 22819 & 352 \\
\hline 11 & 47366 & 321 & 67531 & 356 & 56711 & 326 & 82132 & 317 \\
\hline 12 & 59644 & 312 & 59294 & 358 & 48809 & 326 & 65899 & 323 \\
\hline Average & 68669 & 315 & 61743 & 331 & 44377 & 313 & 53494 & 327 \\
\hline
\end{tabular}

TABLE 2 | Distribution of operational taxonomic units (OTUs) among fungal lineages including the 10 most abundant genera detected in stored peanuts of four storage areas.

\begin{tabular}{lllll}
\hline Taxnomic affinity & \multicolumn{4}{c}{ Percent of reads } \\
\cline { 2 - 5 } & Liaoning & Shandong & Hubei & Guangdong \\
\hline Ascomycota & 93.60 & 72.90 & 92.27 & 86.49 \\
Eurotiomycetes & 70.34 & 30.68 & 86.22 & 85.09 \\
Eurotium & 16.14 & 0.96 & 14.59 & 50.04 \\
Aspergillus & 0.53 & 6.29 & 10.86 & 25.75 \\
Penicillium & 43.86 & 0.79 & 55.51 & 2.69 \\
Emericella & 5.17 & 22.46 & 4.32 & 6.55 \\
Talaromyces & 3.87 & 0.08 & 0.87 & 0.01 \\
Dothideomycetes & 5.66 & 4.18 & 1.62 & 0.11 \\
Alternaria & 1.29 & 0.81 & 0.53 & 0.01 \\
Cladosporium & 2.72 & 2.26 & 0.39 & 0.06 \\
Sordariomycetes & 17.24 & 37.24 & 1.53 & 0.32 \\
Clonostachys & 15.12 & 19.90 & 0.43 & 0.18 \\
Nectriaceae sp. & 0.22 & 7.67 & 0.34 & 0.04 \\
Zygomycota & 0.19 & 26.22 & 0.78 & 0.16 \\
Mucomycotina & 0.18 & 26.21 & 0.77 & 0.16 \\
Rhizopus & 0.18 & 26.21 & 0.77 & 0.16 \\
\hline
\end{tabular}

\section{Results}

\section{Data Characteristics}

Of 52 peanut samples stored in four areas of China, 39 samples were successfully amplified and sequenced. DNA from the peanut samples stored from 0 to 3 months in LN and SD province and 0 to 2 months in HB and GD province could not be amplified. The results suggested that fungi number is lesser in early stages of storage. The results were consistent with the findings of other investigators studying peanuts from Brazil (Rossetto et al., 2005; Nakai et al., 2008) and India (Bhattacharya and Raha, 2002) using traditional approach. They found that the frequencies of fungi, especially Aspergillus sp., were higher in peanut kernels in later stages of storage. In peanut kernels stored in $\mathrm{LN}$, the average number of raw reads generated per sample was 85,099 , of which 74,457 were retained following filtering and denoising steps, and 68,699 reads were subsequently clustered into different OTUs. The number of reads which were clustered into OTUs in LN was highest, followed by SD, GD, and HB (Table 1).

\section{Fungal Diversity in Peanut Kernels in Different Areas}

As shown in Table 2, in peanuts stored in LN, HB and GD, Ascomycota was dominant, $93.60 \%, 92.27 \%$ and $86.49 \%$ of reads belongs to the phylum, respectively. Among Ascomycota, Penicillium, Eurotium, Aspergillus, Emericella, Talaromyces, Clonostachys, Cladosporium, and Alternaria were main genera observed. However, in peanut kernels stored in SD, the dominant phyla were Ascomycota and Zygomycota. Rhizopus, Emericella, Clonostachys, and Aspergillus were predominant genera. The predominant species in Aspergillus were A. flavus and A. penicillioides. In peanuts stored in $\mathrm{LN}, \mathrm{SD}, \mathrm{HB}$ and GD, the average percent of reads of two species were 0.12 and $2.01 \%, 6.39$ and $0.26 \%, 1.41$ and $10.33 \%, 0.22$ and $31.59 \%$, respectively. In Penicillium, $P$. georgiense, Penicillium sp. ASR_162, Penicillium sp. III JH_2010 and Penicillium sp. PSF11 were main fungi species. In Emericella, Talaromyces, Cladosporium, Macrophomina, Clonostachys, and Rhizopus genera, the main species were Emericella nidulans, Talaromyces sp. NRRL 62223, Cladosporium sp. 4 MU_202, Macrophomina phaseolina, Clonostachys rosea, and Rhizopus arrhizus, respectively.

\section{Storage Time and Fungal Diversity}

Significant variation in per-sample OTU richness based on storage time and peanuts varieties stored in different areas was observed (Figure 2). The OTUs number in peanuts stored in $\mathrm{SD}$ was the highest, followed by LN, HB, and GD. The average 


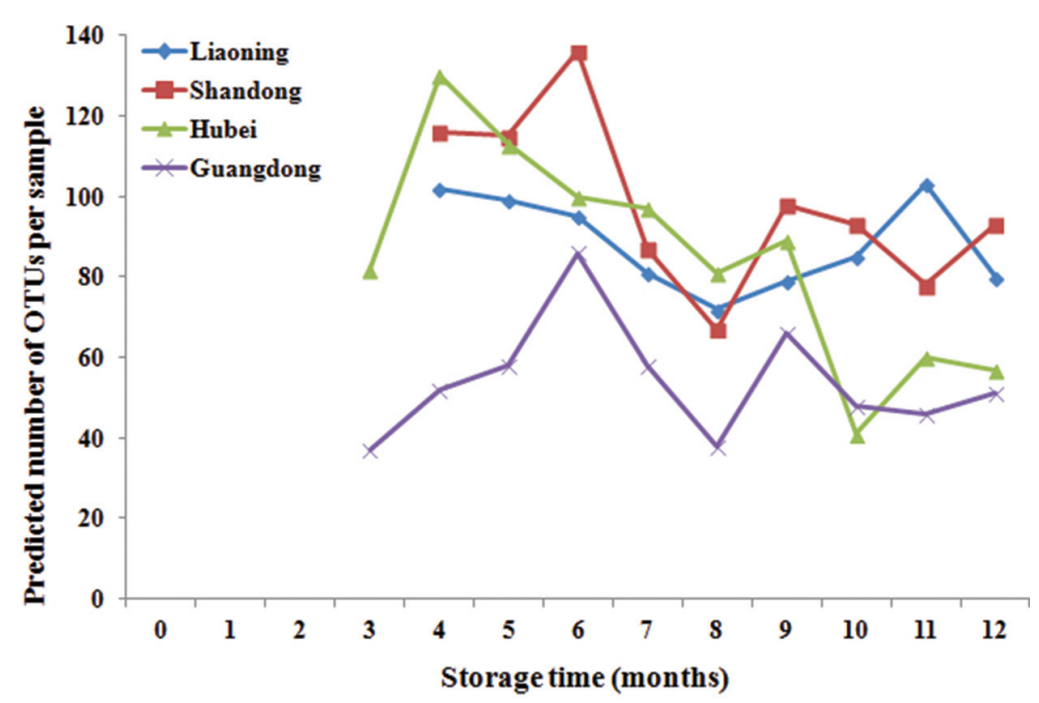

FIGURE 2 | Predicted number of operational taxonomic units (OTUs) per sample in stored peanuts of four storage areas.

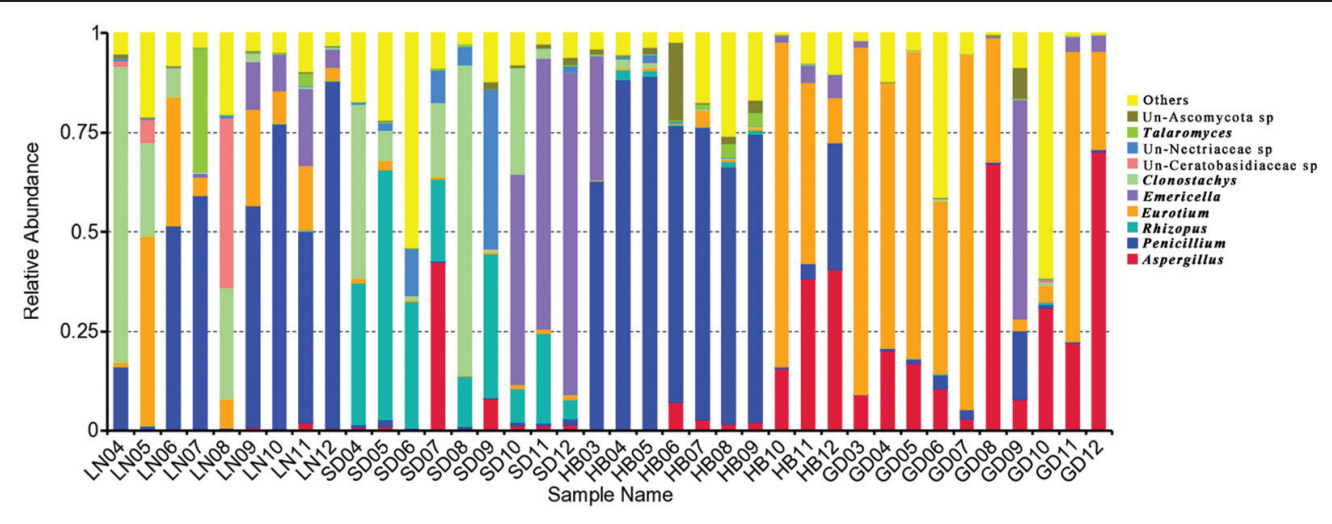

FIGURE 3 | Overall distribution of fungi at genus level in stored peanuts of four storage areas.

number of OTUs per sample in peanuts stored in SD was 98, reaching its highest and lowest value at 6th and 8th months, respectively. The average numbers of OTUs in LN, HB, and GD have the similar trend. These results suggested that the fungi diversities were fluctuated during the storage. In general the fungi diversity was lowest at the 8 th months, when the temperature and $\mathrm{RH}$ were high and suitable for the growth of Ascomycota fungi (Figure 1).

\section{Fungal Community Variation in Genus Level Across Storage Time}

Significant variation in the relative abundance of fungal genera per sample based on storage areas and storage time was observed (Figures 3 and 4). In peanuts of LN, Aspergillus sp. were rare and only had a relative abundance of $0.53 \%$. The relative abundances of Aspergillus sp. at 9th to 12th months were higher than that at 4 th to 8 th months. Aspergillus sp. exhibited a peak in relative abundance at 11th months, while this peak occurred at 7 th, 12th and 12th, in SD, HB, and GD, respectively. In general, the abundances of Aspergillus sp. were higher in later stage of storage than the early stage. The relative abundances of Penicillium sp. in LN was higher than $50 \%$ at the 6 th, 7 th, 9th, 10th, and 12 th months, and exhibited a peak at 12th month, while this peak occurred at 5th, 5th and 9th, in SD, HB, and GD, respectively. In LN and GD, the relative abundances of Emericella sp. were higher at 9 th to 12 th months than the early stages of storage. And in $\mathrm{SD}$ and $\mathrm{HB}$, Emericella sp. sharply increased at 10th month and were higher at 10th to 12th months than other months. These results suggested that the relative abundances of Aspergillus sp. and Emericella sp. increased in the later stage of storage and higher than the early stage of storage.

\section{Isolation and Identification of Aspergillus Fungi from Peanut Kernels}

In the peanut samples the following mycotbiota were isolated: Aspergillus sp. Penicillium sp. Rhizoupus sp. and Fusarium sp. Of the Aspergillus, A. flavus was the most important because of its known toxigenic potential. In the present study, 100 isolates 


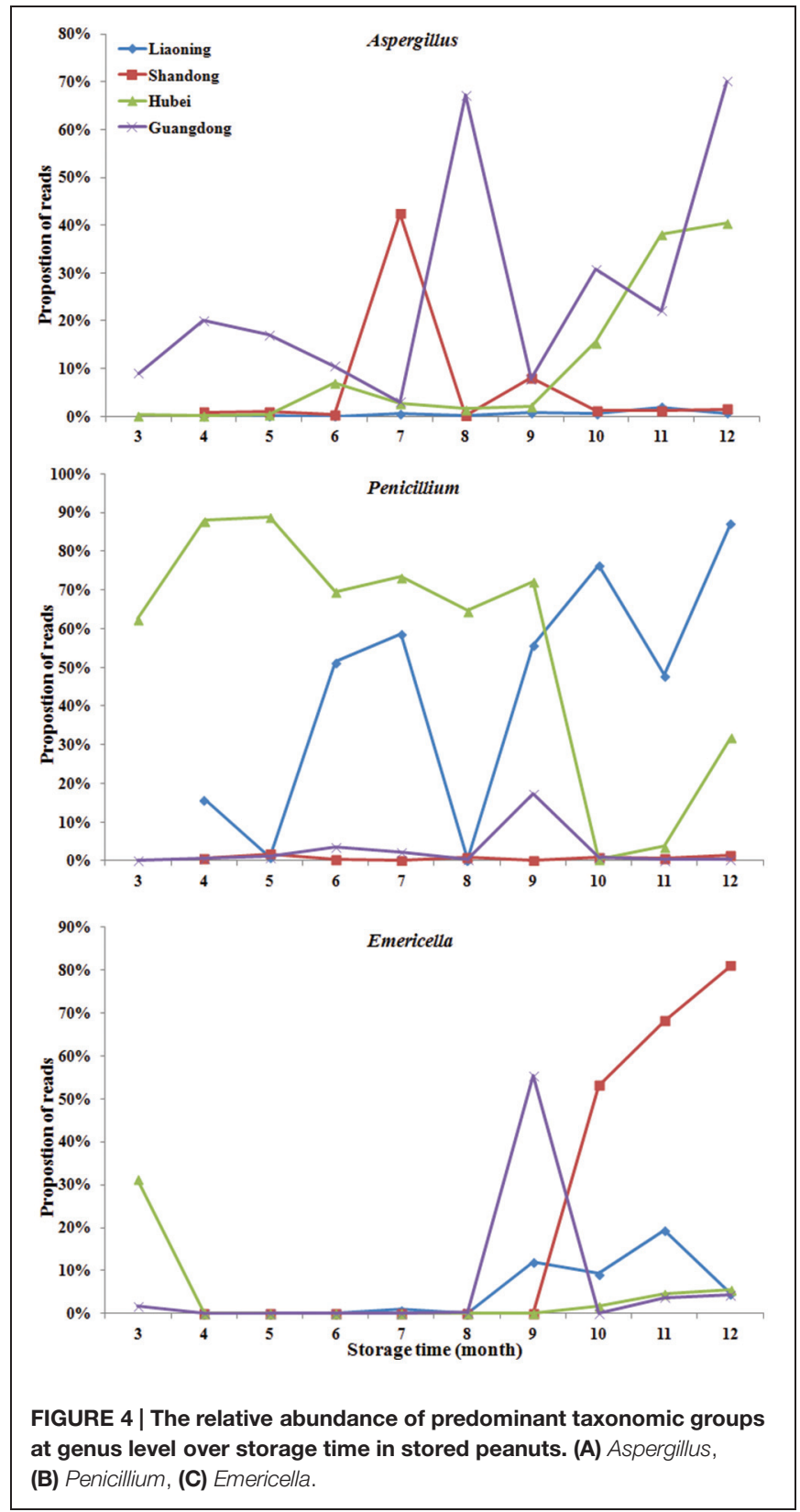

of Aspergillus sp. were sequenced and identified, and A. flavus, A. penicillioides, and $A$. niger were identified. Of them, the percentage of $A$. penicillioides (60\%) was the highest, followed by $A$. flavus (21\%) and A. niger (17\%). On AFPA medium, 21 isolates produced a bright orange reverse and were confirmed to be A. flavus.

\section{Aflatoxin $B_{1}$ in Stored Peanuts}

$\mathrm{AFB}_{2}, \mathrm{AFG}_{1}$, and $\mathrm{AFG}_{2}$ were not detected in all the peanut samples. The variation of $\mathrm{AFB}_{1}$ in peanuts stored in four areas was shown in Table 3. During the first 6 months of the storage, $\mathrm{AFB}_{1}$ was not detected in peanuts of four areas. $\mathrm{AFB}_{1}$ was detected in peanuts of four areas at the 7 th month, then increased and reached the highest level at the 8th or 9th month.
TABLE 3 | Mean levels of aflatoxin $B_{1}$ in stored peanuts.

\begin{tabular}{|c|c|c|c|c|}
\hline $\begin{array}{l}\text { Storage time } \\
\text { (month) }\end{array}$ & Liaoning & Shandong & Hubei & Guangdong \\
\hline 0 & ND & ND & ND & ND \\
\hline 1 & ND & ND & ND & ND \\
\hline 2 & ND & ND & ND & ND \\
\hline 3 & ND & ND & ND & ND \\
\hline 4 & ND & ND & ND & ND \\
\hline 5 & ND & ND & ND & ND \\
\hline 6 & $\mathrm{ND}$ & $\mathrm{ND}$ & ND & ND \\
\hline 7 & $2.63 \pm 0.13$ & $3.25 \pm 0.12$ & $1.48 \pm 0.28$ & $2.29 \pm 0.15$ \\
\hline 8 & $2.87 \pm 0.15$ & $3.52 \pm 0.18$ & $1.51 \pm 0.09$ & $3.65 \pm 0.21$ \\
\hline 9 & $2.65 \pm 0.20$ & $3.61 \pm 0.14$ & $1.59 \pm 0.10$ & $4.03 \pm 0.11$ \\
\hline 10 & $1.02 \pm 0.21$ & $2.18 \pm 0.18$ & ND & $1.27 \pm 0.32$ \\
\hline 11 & ND & ND & ND & ND \\
\hline 12 & ND & ND & ND & ND \\
\hline
\end{tabular}

ND, not detected.

Subsequently, $\mathrm{AFB}_{1}$ levels decreased and were not detectable at 11 th and 12 th months in peanuts of all areas.

\section{Degradation of $\mathrm{AFB}_{1}$ by the Culture Filtrate of A. niger}

The culture of 20 strains of $A$. niger, isolated from the stored peanuts, all could significantly degrade $\mathrm{AFB}_{1}$ with degradation rate of 44.5-100\% (Table 4). Of 20 strains, eight strains of $A$. niger could completely degrade $\mathrm{AFB}_{1}$. Furthermore, $A$. niger $\mathrm{N}-01, \mathrm{~N}-$ 02 , and N-03 reduced $\mathrm{AFB}_{1}$ in peanuts from $62.3 \pm 4.5 \mu \mathrm{g} / \mathrm{kg}$ to undetectable with degradation rate of $100 \%$. The results suggested $A$. niger strains in stored peanuts might have the ability to reduce $\mathrm{AFB}_{1}$ levels in peanuts.

\section{Discussion}

The average numbers of OTUs in peanuts of $\mathrm{LN}, \mathrm{SD}, \mathrm{HB}$, and GD were 88, 98, 85, and 56, respectively, with 33, 43, 35, and 22 fungal genera being identified, respectively. These results showed that the fungal diversity of peanuts stored in SD was the highest, and suggested that the moderate climate of SD was more suitable for maintaining fungal diversity (Figure 1). However, the fungal diversity of peanuts stored in GD was lowest because the temperature and $\mathrm{RH}$ were greatly higher than other areas (Figure 1). Of 22 genera, Eurotium, Aspergillus, Emericella, and Penicillium were the predominant genera, total relative abundance of the four genera was more than $85 \%$.

In general, Eurotium, Penicillium, Aspergillus, Clonostachys, Emericella, and Rhizopus were main genera in peanuts stored in four areas, because of the greater adaptation of these fungi to the substrate, especially during storage (Rossetto et al., 2005; Nakai et al., 2008). The occurrence of Aspergillus, Penicillium, and Rhizopus was similar to the findings of other investigators studying peanuts from Brazil (Rossetto et al., 2005; Nakai et al., 2008) and India (Bhattacharya and Raha, 2002) using traditional isolation, enumeration and identification methods of the mycoflora on DRBC and AFPA media. Eurotium, 
TABLE 4 | The degradation of $\mathrm{AFB}_{1}$ by Aspergillus niger.

\begin{tabular}{|c|c|c|c|c|}
\hline \multirow{2}{*}{$\begin{array}{l}\text { Identification } \\
\text { number }\end{array}$} & \multicolumn{2}{|c|}{ In PDB } & \multicolumn{2}{|c|}{ In kernels } \\
\hline & $\begin{array}{c}\text { AFB }_{1} \\
(\mu \mathrm{g} / \mathrm{kg})\end{array}$ & $\begin{array}{l}\text { Degradation } \\
\text { rate }(\%)\end{array}$ & $\begin{array}{c}\text { AFB }_{1} \\
(\mu \mathrm{g} / \mathrm{kg})\end{array}$ & $\begin{array}{l}\text { Degradation } \\
\text { rate }(\%)\end{array}$ \\
\hline Control & $80.2 \pm 5.5$ & 0 & $62.3 \pm 4.5$ & 0 \\
\hline $\mathrm{N}-01$ & 0 & 100 & 0 & 100 \\
\hline $\mathrm{N}-02$ & 0 & 100 & 0 & 100 \\
\hline $\mathrm{N}-03$ & 0 & 100 & 0 & 100 \\
\hline $\mathrm{N}-04$ & $10.0 \pm 4.2^{* *}$ & 90.0 & $14.3 \pm 3.5^{* *}$ & 77.0 \\
\hline N-05 & $21.4 \pm 7.5^{* *}$ & 78.6 & $36.5 \pm 4.3^{*}$ & 41.4 \\
\hline $\mathrm{N}-06$ & 0 & 100 & $8.5 \pm 1.4^{* *}$ & 86.4 \\
\hline N-07 & $6.4 \pm 3.1^{* *}$ & 93.6 & $11.8 \pm 2.6^{* *}$ & 81.1 \\
\hline $\mathrm{N}-08$ & 0 & 0 & $9.1 \pm 1.3^{* *}$ & 85.4 \\
\hline N-09 & $11.0 \pm 1.4^{* *}$ & 89.0 & $16.9 \pm 4.2^{* *}$ & 72.9 \\
\hline $\mathrm{N}-10$ & $20.1 \pm 1.9^{* *}$ & 79.9 & $40.6 \pm 6.4^{*}$ & 34.8 \\
\hline $\mathrm{N}-11$ & 0 & 100 & $12.5 \pm 3.1^{* *}$ & 79.9 \\
\hline $\mathrm{N}-12$ & $10.7 \pm 1.9^{* *}$ & 89.3 & $16.4 \pm 4.3^{* *}$ & 73.7 \\
\hline$N-13$ & $13.0 \pm 0.5^{* *}$ & 87.0 & $18.2 \pm 5.4^{* *}$ & 70.8 \\
\hline $\mathrm{N}-14$ & 0 & 100 & $10.5 \pm 1.7^{* *}$ & 83.1 \\
\hline $\mathrm{N}-15$ & 0 & 100 & $13.6 \pm 1.8^{* *}$ & 78.2 \\
\hline $\mathrm{N}-16$ & $12.4 \pm 1.4^{* *}$ & 87.6 & $18.7 \pm 4.1^{* *}$ & 70.0 \\
\hline $\mathrm{N}-17$ & 0 & 100 & $13.5 \pm 3.4^{* *}$ & 78.3 \\
\hline $\mathrm{N}-18$ & $10.0 \pm 1.9^{* *}$ & 90.0 & $15.8 \pm 3.5^{* *}$ & 74.6 \\
\hline $\mathrm{N}-19$ & $14.0 \pm 1.9^{* *}$ & 86.0 & $24.5 \pm 3.1^{* *}$ & 60.7 \\
\hline $\mathrm{N}-20$ & $55.5 \pm 8.5^{* *}$ & 44.5 & $60.4 \pm 8.7$ & 3.0 \\
\hline
\end{tabular}

*Statistically significant when compared to Control, $P<0.05$; ** Statistically significant when compared to Control, $P<0.01$.

Clonostaschys, and Emericella were not detected in these studies as they did not grow well on DRBC or AFPA media.

During the storage, in general the relative abundances of Aspergillus were higher at 7 th to 12 th months than the first 6 months. The highest value in LN, SD, HB, and GD were observed at the 11th, 7th, 12th, and 12th months, respectively. In particular, the relative abundances of peanuts stored in $\mathrm{HB}$ sharply increased from 9 to 12 months reaching the highest value $40.40 \%$. The result was consistent with the findings of other investigators studying peanuts from Brazil (Rossetto et al., 2005; Nakai et al., 2008) and India (Bhattacharya and Raha, 2002) using traditional approaches. They found that the frequencies of Aspergillus sp. were higher in peanut kernels at 7 th to 12 th months than the first 6 months. On the other hand, the increase in the frequency of Aspergillus sp. can be explained by the fact of that this fungus and Penicillium sp. are considered to be storage fungi (Nakai et al., 2008; Krijgsheld et al., 2012). These results confirmed that the risks of peanuts contaminated with aflatoxins increased over storage time, especially after 6 months.

During storage from 7 th to 10 th months, $\mathrm{AFB}_{1}$ increased and was high because it was summer with the highest temperature and $\mathrm{RH}$. However, $\mathrm{AFB}_{1}$ concentrations were lower than $5 \mu \mathrm{g} / \mathrm{kg}$ during storage. Studies conducted in China analyzing the occurrence of aflatoxins in peanuts and derived products generally reported similar contamination levels (Ding et al., 2012). Furthermore, the relative abundances of $A$. flavus were low $(0.06-6.04 \%)$. The result mainly be attributed to low $a_{\mathrm{w}}$ (0.40-0.70; Figure 5) which was below the minimum range of

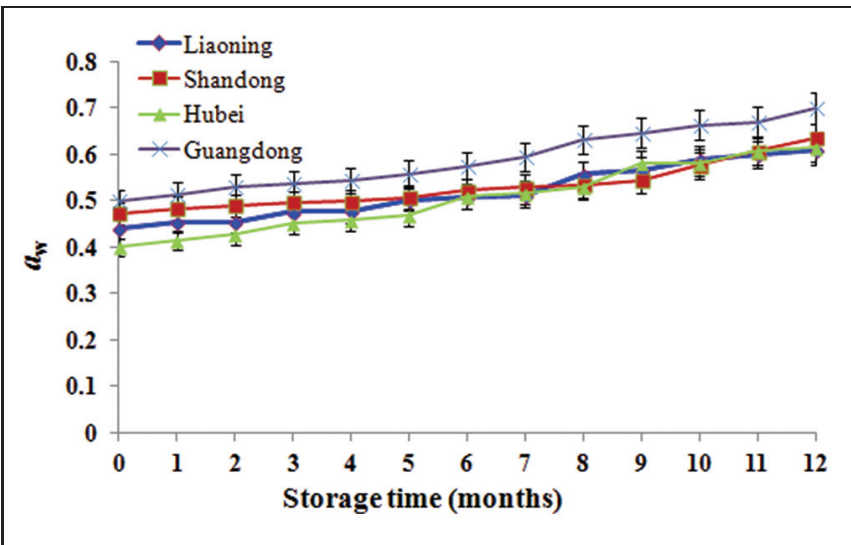

FIGURE 5 | The water activity $\left(a_{w}\right)$ of stored peanuts over storage time.

0.70-0.80 established for the growth of A. flavus (Hocking, 1997) and the minimum range of $0.80-0.90$ for aflatoxins production (Passone et al., 2010, 2012). Furthermore, the mean temperature ranged from -1 to $30^{\circ} \mathrm{C}$ and the $\mathrm{RH}$ ranged from 48 to $83 \%$ (Figure 1). Thus, the temperature was below $32-33^{\circ} \mathrm{C}$ considered to be the optimum temperature for the growth of $A$. flavus by Hocking (1997), the RH was lower than $83-85 \%$ considered to favor the growth of A. flavus (Christensen et al., 1977). Kaaya and Kyamuhangire (2006) obtained the similar results. They found that aflatoxin levels of maize kernels stored for more than 6 months were higher than their counterparts stored for 2-6 months. However, Nakai et al. (2008) found the absence of significant correlations between the presence of $\mathrm{AFB}_{1}$ and $\mathrm{AFB}_{2}$ in peanut kernels, storage time and abiotic factors.

At 9th to 12th months, the relative abundances of Aspergillus sp. increased over storage time, especially in peanuts of $\mathrm{HB}$ and GD. However, $\mathrm{AFB}_{1}$ concentration of peanuts decreased over times during the same period. So, it was postulated that $\mathrm{AFB}_{1}$ reduction was due to degradation by other fungi or binding with other compounds of peanuts. Cvetnić and Pepeljnjak (2007) showed that some mold species such as Alternaria sp., Cladosporium sp., Mucor sp. and A. niger, could effectively inhibit the mycelia growth of $A$. flavus and reduce the $\mathrm{AFB}_{1}$ production with co-culturing in yeast extract sucrose (YES) broth. In particular, the interaction of $A$. niger with $A$. flavus against production of $\mathrm{AFB}_{1}$ has been reported. Nevertheless, the mechanism of $\mathrm{AFB}_{1}$ reduction by $A$. niger was still debatable. Horn and Wicklow (1983) indicated that A. niger lowered substrate to acidic $\mathrm{pH}$ value to suppress $\mathrm{AFB}_{1}$ formation. Shantha et al. (1990) demonstrated that oxalic acid and gluconic acid secreted by $A$. niger could prevent $\mathrm{AFB}_{1}$ production (Shantha and Rati, 1990; Shantha et al., 1990). However, some recent researches indicated that an antifungal peptide (AFP) isolated from $A$. niger could inhibit the growth of $A$. flavus and $\mathrm{AFB}_{1}$ biosynthesis (Lee et al., 1999; Xu et al., 2013). In addition, Xu et al. (2013) in their studies also found that the culture filtrate of strain FS10 could effectively degrade $\mathrm{AFB}_{1}$. Interestingly, in the present study, we also found 20 strains of $A$. niger from stored peanuts could degrade $\mathrm{AFB}_{1}$. Furthermore, $A$. niger $\mathrm{N}-01, \mathrm{~N}-02$, and $\mathrm{N}-03$ could reduce $A F B_{1}$ in peanuts. 
The present study is the first study that provides a more comprehensive profile of the mycobiome and its variation in stored peanuts using ITS2 sequencing technology. The fungal diversity of peanuts stored in SD was the highest with 98 OTUs and 43 genera, followed by LN, HB, and GD. In peanuts, Aspergillus, Rhizopus, Emericella, Penicillium, Eurotium, and Clonostachys were predominant. The abundance of Aspergillus increased over the latitude (from LN to GD), confirming that the higher temperature and $\mathrm{RH}$ may result in the higher risk of peanuts contaminated with Aspergillus and aflatoxins. During the storage, Aspergillus levels at 7-12 months were higher than first 6 months, suggesting the risk will increase over storage time. During storage 7-10 months, $\mathrm{AFB}_{1}$ increased and was high in four areas, and then decreased. The reduction of $\mathrm{AFB}_{1}$ might be attributed to the degradation of $\mathrm{AFB}_{1}$ by $A$. niger or binding with other compounds of peanuts.

\section{Author Contributions}

YL, XD and FX designed the experiments; ND, FX, XL, JNS, LW, YZ, YW, performed the experiments; FX analyzed the

\section{References}

AOAC International (2000). "Natural contaminatants," in Official Methods of the Association of Official Analytical Chemists, 17th Edn, ed. P. Cunnif (Gaithersburg: AOAC International), [section 994.08].

Arfi, Y., Buée, M., Marchand, C., Levasseur, A., and Record, E. (2012). Multiple markers pyrosequencing reveals highly diverse and host-specific fungal communities on the mangrove trees Avicennia marina and Rhizophora stylosa. FEMS Microbiol. Ecol. 79, 433-444. doi: 10.1111/j.1574-6941.2011. 01236.x

Berjak, P. (1984). Report of seed storage committee working group on the effects of storage fungi on seed viabiligy. 1980-1983. Seed Sci. Technol. 12, 233-253.

Bhattacharya, K., and Raha, S. (2002). Deteriorative changes of maize, groundnut and soybean seeds by fungi in storage. Mycopathologia 155, 135-141. doi: 10.1023/A:1020475411125

Boller, R. A., and Schroeder, H. W. (1973). Influence of Aspergillus chevalieri on production of aflatoxin in rice by Aspergillus parasiticus. Phytopathology 63, 1507-1510. doi: 10.1094/Phyto-63-1507

Boller, R. A., and Schroeder, H. W. (1974). Influence of Aspergillus candidus on production of aflatoxin in rice by Aspergillus flavus. Phytopathology 64, 121-123. doi: 10.1094/Phyto-64-121

Christensen, C. M., Mirocha, C. J., and Meronuck, R. A. (1977). Molds, Mycotoxins And Mycotoxicoses. Minnesota: American Association of Cereal Chemists, 142.

Costello, E. K., Lauber, C. L., Hamady, M., Fierer, N., Gordon, J. I., and Knight, R. (2009). Bacterial community variation in human body habitats across space and time. Science 326, 1694-1697. doi: 10.1126/science.1177486

Cvetnić, Z., and Pepeljnjak, S. (2007). Interaction between certain moulds and aflatoxin $\mathrm{B}_{1}$ producer Aspergillus flavus NRRL 3251. Arh. Hig. Rada Toksikol. 58, 429-434. doi: 10.2478/v10004-007-0036-0

Ding, X., Li, P., Bai, Y., and Zhou, H. (2012). Aflatoxin $B_{1}$ in postharvest peanuts and dietary risk in China. Food Control 23, 143-148. doi: 10.1016/j.foodcont.2011.06.026

Ghannoum, M. A., Jurevic, R. J., Mukherjee, P. K., Cui, F., Sikaroodi, M., Naqvi, A., et al. (2010). Characterization of the oral fungal microbiome (mycobiome) in healthy individuals. PLoS Pathog. 6:e1000713. doi: 10.1371/journal.ppat.1000713

Gillever, P., Siskaroodi, M., Keshavarzian, A., and Mudu, E. (2010). Quantitative assessment of the human gut microbiome using multitag pyrosequencing. Chem. Biodivers. 7, 1065-1075. doi: 10.1002/cbdv.200900322 sequencing data; ND analyzed the aflatoxins determination data; $\mathrm{XL}$ analyzed the AFB1 degradation data; WG provided scientific expertise; FX wrote the manuscript; YL and JNS edited the manuscript.

\section{Acknowledgments}

We gratefully acknowledge the financial support of National Basic Research Program of China (973 program, 2013CB127801), Special Fund for Agro-scientific Research in the Public Interest (201203037).

\section{Supplementary Material}

The Supplementary Material for this article can be found online at: http://journal.frontiersin.org/article/10.3389/fmicb. 2015.01055

FIGURE S1 | Agrose electrophoresis of total microbiome genomic DNA extraction from stored peanut kernels.

Giorni, P., Magan, N., and Battilani, P. (2009). Environmental factors modify carbon nutritional patterns and niche overlap between Aspergillus flavus and Fusarium verticillioides strains from maize. Int. J. Food Microbiol. 130, 213-218. doi: 10.1016/j.ijfoodmicro.2009.01.032

Gonçalez, E., Nogueira, J. H. C., Fonseca, H., Felicio, J. D., Pino, F. A., and Corrêa, B. (2008). Mycobiota and mycotoxins in Brazilian peanut kernels from sowing to harvest. Int. J. Food Microbiol. 123, 184-190. doi: 10.1016/j.ijfoodmicro.2008.01.012

Grice, E. A., Kong, H. H., Conlan, S., Deming, C. B., Davis, J., Young, A. C., et al. (2009). Topographical and temporal diversity of the human skin microbiome. Science 324, 1190-1192. doi: 10.1126/science.11 71700

Hocking, A. D. (1997). “Toxigenic Aspergillus species," in Food Microbiology: Fundamentals and Frontiers, eds M. P. Doyle, L. R. Beuchat, and T. J. Montville (Washington, DC: ASM Press), 393-405.

Horn, B. W., and Wicklow, D. T. (1983). Factors influencing the inhibition of aflatoxin production in corn by Aspergillus niger. Can. J. Microbiol. 29, 1087-1091. doi: 10.1139/m83-167

Hussein, S. H., and Brasel, J. M. (2001). Toxicity, metabolism, and impact of mycotoxins on humans and animals. Toxicology 167, 101-134. doi: $10.1016 /$ S0300-483X(01)00471-1

International Agency for Research on Cancer [Iarc, \#186] (1993). Some naturally occurring substances: food items and constituents, heterocyclic aromatic amines and mycotoxins. IARC Monogr. Eval. Carcinog. Risks Hum. 56, $1-599$.

International Agency for Research on Cancer [Iarc, \#186] (2002). Some traditional herbal medicines, some mycotoxins, naphthalene and styrene. IARC Monogr. Eval. Carcinog. Risks Hum. 82, 1-556.

Kaaya, A. N., and Kyamuhangire, W. (2006). The effect of storage time and agroecological zone on mould incidence and aflatoxin contamination of maize from traders in Uganda. Int. J. Food Microbiol. 110, 217-223. doi: 10.1016/j.ijfoodmicro.2006.04.004

Krijgsheld, P., Bleichrodt, R., van Velum, G. J., Wang, F., Muller, W. H., Dijksterhuis, J., et al. (2012). Development in Aspergillus. Stud. Mycol. 74, 1-29. doi: $10.3114 /$ sim0006

Krishnamurthy, Y. L., and Shashikala, J. (2006). Inhibition of aflatoxin B1 production of Aspergillus flavus, isolated from soybean seeds by certain natural plant products. Lett. Appl. Microbiol. 43, 469-474. doi: 10.1111/j.1472765X.2006.02011.X 
Lauber, C. L., Hamady, M., Knight, R., and Fierer, N. (2009). Pyrosequencingbased assessment of soil $\mathrm{pH}$ as a predictor of soil bacterial community structure at the continental scale. Appl. Environ. Microbiol. 75, 5111-5120. doi: 10.1128/AEM.00335-09

Lee, D. G., Shin, S. Y., Maeng, C.-Y., Jin, Z. Z., Kim, K. L., and Hahm, K.-S. (1999). Isolation and characterization of a novel antifungal peptide from Aspergillus niger. Biochem. Biophys. Res. Commun. 263, 646-651. doi: 10.1006/bbrc.1999.1428

Liu, X., Wang, J., Li, F., Ji, R., Chen, J., Yao, X., et al. (2006). Determination of Aflatoxins $B_{1}, B_{2}, G_{1}, G_{2}$ in Foods. Beijing: National Standards of P. R. China. GB/T 5009. 23-2006.

Magoc, T., and Salzberg, S. L. (2011). FLASH: fast length adjustment of short reads to improve genome assemblies. Bioinformatics 27, 2957-2963. doi: 10.1093/bioinformatics/btr507

Maing, I. Y., Ayres, J. C., and Koehler, P. E. (1973). Persistence of aflatoxin during the fermentation of soy sauce. Appl. Microbiol. 25, 1015-1017. doi: 10.3852/11-027

Mello, A., Napoli, C., Murat, C., Morin, E., Marceddu, G., and Bonfante, P. (2011). ITS-1 versus ITS-2 pyrosequencing: a comparison of fungal populations in truffle grounds. Mycologia 103, 1184-1193. doi: 10.3852/11-027

Nakai, V. K., Rocha, L. D. O., Gonçalez, E., Fonseca, H., Ortega, E. M. M., and Corrêa, B. (2008). Distribution of fungi and aflatoxins in a stored peanut variety. Food Chem. 106, 285-290. doi: 10.1016/j.foodchem.2007.05.087

Passone, M. A., Rosso, L. C., Ciancio, A., and Etcheverry, M. (2010). Detection and quantification of Aspergillus section Flavi sp. in stored peanuts by real-time PCR of nor-1 gene, and effects of storage conditions on aflatoxin production. Int. J. Food Microbiol. 138, 276-281. doi: 10.1016/j.ijfoodmicro.2010.01.003

Passone, M. A., Rosso, L. C., and Etcheverry, M. (2012). Influence of sublethal antioxidant doses, water potential and temperature on growth, sclerotia, aflatoxins and aflD (=nor-1) expression by Aspergillus flavus RCP08108. Microbiol. Res. 167, 470-477. doi: 10.1016/j.micres.201 1.11 .004

Pitt, J. I., and Hocking, A. D. (1997). Fungi and Food Spoilage. London: Champman \& Hall, 593 .

Pitt, J. I., Hocking, A. D., Bhudhasamai, K., Miscamble, B. F., Wheeler, K. A., and Tanboon-Ek, P. (1993). The normal mycobiota of commodities from Tailand. 1. Nuts and oilseeds Int. J. Food Microbiol. 20, 211-226. doi: 10.1016/0168 1605(93)90166-E

Pitt, J. I., Hocking, A. D., and Glenn, D. R. (1983). An improved medium for the dection of Aspergillus flavus and A. parasiticus. J. Appl. Bacteriol. 54, 109-114. doi: 10.1111/j.1365-2672.1983.tb01307.x
Roesch, L. F., Fulthorpe, R. R., Riva, A., Casella, G., Hadwin, A. K., Kent, A. D., et al. (2007). Pyrosequencing enumerates and contrasts soil microbial diversity. ISME J. 1, 283-290. doi: 10.1038/ismej.2007.53

Rossetto, C., Silva, O., and Araújo, A. (2005). Influência da calagem, da época de colheita e da secagem na incidência de fungos e aflatoxinas em grãos de amendoim armazenados. Cienc. Rural 35, 309-315. doi: 10.1590/S010384782005000200010

Shantha, T., and Rati, E. R. (1990). Isolation and characterization of an aflatoxin inhibiting metabolite from A. niger. Curr. Sci. 59, 326-327.

Shantha, T., Rati, E. R., and Shankar, T. N. B. (1990). Behaviour of Aspergillus flavus in presence of Aspergillus niger during biosynthesis of aflatoxin $\mathrm{B}_{1}$. Antonie Van Leeuwenhoek 58, 121-127. doi: 10.1007/BF00422728

Smith, J. E., and Ross, I. C. (1991). “The toxigenic Aspergillus," in Mycotoxins and Animal Foods, eds J. E. Smith and R. S. Henderson (London: CRC Press), 31-61.

Sogin, M. L., Morrison, H. G., Huber, J. A., Welch, D. M., Huse, S. M., Neal, P. R., et al. (2006). Microbial diversity in the deep sea and the underexplored "rare biosphere." Proc. Natl. Acad. Sci. U.S.A. 103, 12115-12120. doi: $10.1073 /$ pnas.0605127103

Wang, Q., Garrity, G. M., Tiedje, J. M., and Cole, J. R. (2007). Naive Bayesian classifier for rapid assignment of rRNA sequences into the new bacterial taxonomy. Appl. Environ. Microbiol. 73, 5261-5267. doi: 10.1128/AEM.00 062-07

Xu, D., Wang, H., Zhang, Y., Yang, Z., and Sun, X. (2013). Inhibition of nontoxigenic Aspergillus niger FS10 isolated from Chinese fermented soybean on growth and aflatoxin $\mathrm{B}_{1}$ production by Aspergillus flavus. Food Control 32, 359-365. doi: 10.1016/j.foodcont.2012.12.013

Zhou, H. W., Li, D. F., Tam, N. F., Jiang, X. T., Zhang, H., Sheng, H. F., et al. (2011). BIPES, a cost-effective high-throughput method for assessing microbial diversity. ISME J. 5, 741-749. doi: 10.1038/ismej.2010.160

Conflict of Interest Statement: The authors declare that the research was conducted in the absence of any commercial or financial relationships that could be construed as a potential conflict of interest.

Copyright (c) 2015 Ding, Xing, Liu, Selvaraj, Wang, Zhao, Wang, Guo, Dai and Liu. This is an open-access article distributed under the terms of the Creative Commons Attribution License (CC BY). The use, distribution or reproduction in other forums is permitted, provided the original author(s) or licensor are credited and that the original publication in this journal is cited, in accordance with accepted academic practice. No use, distribution or reproduction is permitted which does not comply with these terms. 